\title{
REPORT ON THE SPORTS INJURIES COURSE RUN BY THE INSTITUTE OF ACCIDENT SURGERY
}

\author{
N. TUBBS, FRCS
}

\author{
The General Hospital, Steelhouse Lane, BIRMINGHAM
}

On Friday, 21st September the Institute of Accident Surgery held an inaugural one day course on Sports Injuries at the University of Birmingham. This was a course devoted entirely to the diagnosis and treatment of injury in sport and did not include other medical aspects of sport. The content was aimed at registrar level and was attended by about 40 delegates, mainly orthopaedic registrars.

Surgeon Rear Admiral S. Miles opened the meeting with an interesting short talk on the joy and value of participating in sport and the importance of treating the resultant injuries in a manner likely to return the participant to their sport. Dr. I. D. Adams gave a most lucid account of the difficulties of running a sports injuries clinic. Mr. G. Lemon, described injuries of the foot and included a description of several intrinsic injuries of the foot which were new to many of the audience. After coffee Dr. N. C. C. Sharp spoke on the stresses imposed by the coach. As a physiologist he described the physiological background to training and competing with particular regard to muscle function and dysfunction. For many of us this turned out to be the highlight of the day and gave food for thought as to how one should try to treat and prevent muscle injury. Mr. N. Tubbs followed this with a description of some of the intrinsic injuries around the knee, making particular mention of the medial shelf syndrome and the traction disorders of the quadriceps mechanism. He made a plea for the early diagnosis of these lesions and noted the use of the arthroscope in the diagnosis and sometimes treatment of many knee conditions.

In the afternoon Mr. J. Kenwright described many of the intrinsic injuries to the lower limb and included some of the important conditions of the pelvis. He abolished some of the nonsensical jargon, which is often used in descriptions of sports injuries and described many of these conditions on an anatomical and pathological basis. Pubic symphysitis was given as one of the causes of "groin strain" despite dccurate pathological definition of this condition, it was noted that the various forms of treatment were not particularly successful. Miss. M. K. Patrick spoke on physiotherapy in sports injuries; the various forms of physiotherapy which could be used and abused in the treatment of sports injuries were described, noting ultrasound, of which she was an originator in this Country. Mr. J. E. Buck gave a characteristically interesting talk on injuries of the back and described his own operation for spondylolysis and spondylolysthesis, which was greatly enjoyed by the orthopaedic surgeons. Mr. T. J. Stahl gave the final talk with a complete and well illustrated description of upper limb injuries in sport.

The day was concluded with an excellent dinner at the University Staff House. There had been ample opportunity during the day for meeting old friends and making new ones and it was felt that some of the value of the day was the informal discussion between the various talks. It seems likely that the Institute of Accident Surgery will feel encouraged to run a similar course next year. 